\title{
Imagem e palavra na leitura de narrativa
}

\author{
Flávia Brocchetto Ramos* \\ Neiva Senaide Petry Panozzo \\ Taciana Zanolla ${ }^{* * *}$
}

\section{Resumo}

A produção infantil contemporânea explora as várias linguagens constitutivas da obra literária infantil - palavra e ilustração. A leitura dessas obras possibilita ao leitor a construção de significados na interação entre os códigos verbal e visual. A fim de investigar esse processo de leitura realizado a partir da interaçáo com a linguagem verbal e visual, realiza-se estudo sobre a narrativa $A h$, cambaxirra, se eu pudesse..., de Ana Maria Machado e Graça Lima (2003). Enfocam-se dois aspectos: a análise de possibilidades de leitura propostas pelas linguagens, a partir de estudos de Genette (1982), Iser (1976), Kleiman (2002), Parsons (1992) e Zilberman (1998), e os sentidos construídos por crianças de terceira série do ensino fundamental, seguindo princípios de pesquisa qualitativa (BAUER; GASKELL, 2003; EISNER, 1998). O estudo confirma a ampliação de sentidos do texto, pela inter-relação entre as linguagens. Entretanto, a análise da leitura das crianças sinaliza que os sentidos construídos privilegiam a palavra, em detrimento de aspectos visuais. A perspectiva observada na leitura infantil é efeito da abordagem da literatura na escola, que não forma leitores proficientes. $\mathrm{O}$ artigo objetiva contribuir para pesquisas na área como também para instrumentalizar mediadores de leitura.

Palavras-chave: Leitura. Literatura Infantil. Ilustração.

* Doutora em Letras pela PUCRS. Professora e pesquisadora no PPGEd/UCS.

** Doutora em Educação pela UFRGS. Professora do Centro de Educação e de Filosofia, na Universidade de Caxias do Sul. Pesquisadora na área de leitura e semiótica na Universidade de Caxias do Sul e na UFRGS.

*** Licenciada em Letras pela Universidade de Caxias do Sul. Bolsista de Iniciação Científica no projeto "A produção de sentido e a interação texto-leitor na literatura infantil", entre maio de 2004 e fevereiro de 2006. Professora na rede Municipal de Ensino de Caxias do Sul. 


\section{Introdução}

Desde sua origem, no século XVII, com os contos de Perrault, a literatura infantil explora palavra e ilustração. Na capa de Histoires ou Contes du temps passé avec des moralitez, ${ }^{1}$ de Charles Perrault, publicada em Paris, em 1967, há a imagem de uma velha senhora e três crianças, as quais parecem escutar atentamente a narração de uma história. No interior daquela edição, há vinhetas que, juntamente com a palavra, contribuem para a significaçấo da obra.

Essa tendência do gênero vem sendo reforçada nas obras infantis publicadas recentemente ${ }^{2}$ em virtude de que se observa uma maior exploração das possibilidades de interação entre os códigos verbal e visual. ${ }^{3}$ Nas livrarias e bibliotecas encontram-se obras em que a palavra faz parte da ilustração; há também livros nos quais a imagem está presente em meio ao código verbal. Podemos citar, como exemplo de livros que exploram esses recursos, Planeta Caiqueria, de Hermes Bernardi Júnior (2003) com ilustraçōes de André Neves, e Os bolsos do mundo, escrito por Fabiana Tasca Perin (2003) e ilustrado por Joana Puglia. André Neves apresenta letras e trechos de textos recortados como elementos da ilustraçáo de Planeta Caiqueria. De caixas saem letras, que também formam palavras, enquanto os recortes de textos fazem parte dos cenários. Na obra poética Os bolsos do mundo algumas frases estáo dispostas de forma ondulada, acompanhando os movimentos das crianças que brincam. A ligação entre a linguagem visual e a verbal é feita de forma explícita pelo cordáo que sai dos bolsos das crianças e contorna a palavra "cordáozinho" (Figura 1). Algumas

Figura 1 - Bolsos do mundo

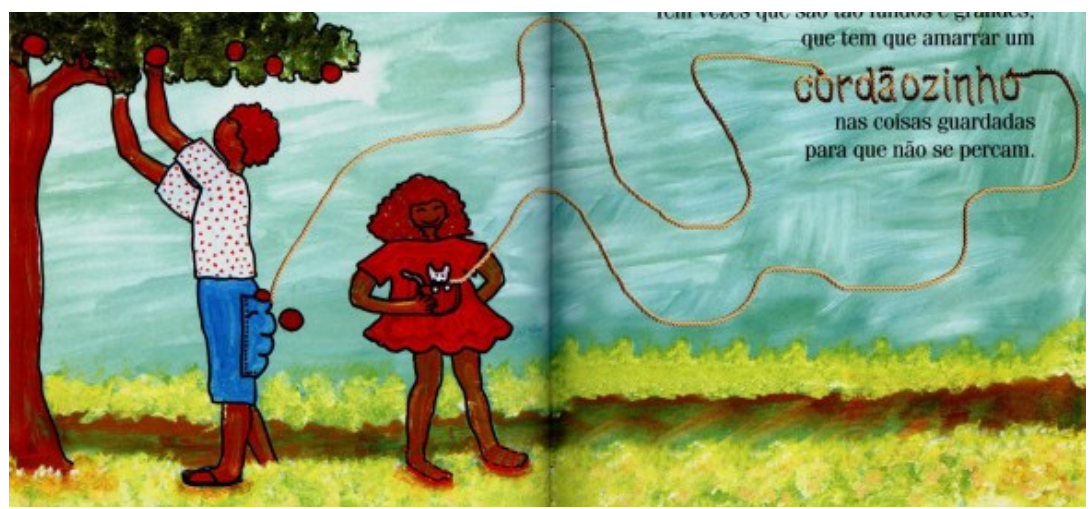

Fonte: PERIN, 2003. Os bolsos do mundo. Ilustração: Joana Puglia, 2003. 
publicaçóes recentes chegam a incluir recursos diferenciados, como sons e peças móveis ou em relevo, aguçando a curiosidade do leitor e, mais do que nunca, convidando-o a explorar o livro, observá-lo e manuseá-lo.

A presença de mais de uma linguagem no suporte livro exige que o leitor interaja com esses códigos para a efetivação de sentido. Dessa forma, surge a necessidade de se estudar peculiaridades desses textos e seus processos de leitura, a fim de identificar habilidades necessárias para a leitura e de criar estratégias que favoreçam seu desenvolvimento. Resultados de avaliaçóes como as do PISA (Programme for International Student Assessment, da Organização para Cooperação e Desenvolvimento Econômico - OCDE) e do ENEM (Exame Nacional de Ensino Médio), cujas matrizes priorizam a leitura, denunciam as restriçóes do estudante brasileiro no que se refere às habilidades de leitura e corroboram essa percepção. De acordo com os resultados desses testes, os alunos têm dificuldade para ler até pequenos enunciados. Frente a esse quadro, aponta-se não apenas a necessidade de investigar os processos de leitura, mas também de investir na formação do leitor, seja professor, seja aluno.

Sabe-se que cada tipo de texto implica um pacto de leitura. Neste estudo, enfoca-se a narrativa literária para a infância, gênero presente nas escolas, como uma modalidade textual na qual palavra e ilustração convivem no objeto livro. Dessa forma, o interlocutor, ao ler, precisa estar atento a essas linguagens, interagindo com as mesmas e relacionando-as para atribuir sentido ao texto. Esse processo prevê um leitor competente, capaz de interagir com palavra e ilustração na significação da obra.

A leitura de narrativas literárias verbo-visuais é realizada nas salas de aula, em geral nas séries iniciais do Ensino Fundamental. Como essa prática exige habilidades específicas, relacionadas à natureza desse texto, acredita-se que cabe à escola preparar seus alunos-leitores para a interação com esse gênero. Isso significa investir no desenvolvimento da competência de leitura das crianças, enfocando, entre outros gêneros, a narrativa verbo-visual. Nesse processo, é imprescindível que o professor seja um leitor competente e esteja capacitado a atuar como mediador do texto, auxiliando o aluno a rever leituras equivocadas e a ampliar os sentidos construídos por meio da percepção e significação de aspectos da obra ainda não observados. A leitura de narrativas verbo-visuais na escola, sob essa ótica, contribui não apenas para a formação de leitores proficientes, mas oferece à criança meios de exercer sua cidadania, 
seja em sua condição de infante, seja na idade adulta, pois lhe permite o acesso à informação e ao conhecimento veiculados pela linguagem verbal e pela visual. Considere-se náo apenas o conhecimento presente nas narrativas literárias escolares, fundamental na formação das crianças, mas também a infinidade de informaçóes presentes em textos do cotidiano, como manchetes, slogans, peças publicitárias, notícias e propagandas, entre outros. Dessa forma, a instrumentalização para a leitura proporciona a inclusão do infante nos âmbitos da cultura letrada, da sociedade e da própria condição humana.

A fim de contribuir para essa demanda de pesquisa desenvolveu-se o projeto de investigação "A produção de sentido e a interação texto-leitor na literatura infantil". O seu objetivo principal é o de investigar a ocorrência do sincretismo discursivo de linguagens em obras de literatura infantil na presença da palavra e da imagem e o modo como isso concorre para a construção de significação nas obras contemporâneas a partir da interação do leitor com os códigos constituintes dos livros selecionados.

Durante a pesquisa, analisou-se a constituição de narrativas infantis contemporâneas, em especial, Indo não sei aonde buscar náo sei o que, de Ângela Lago (2000), Exercício de ser criança, de Manoel de Barros (1999), e Ah, cambaxirra, se eu pudesse..., de Ana Maria Machado (2003). Após estudar os procedimentos presentes nas obras, realizou-se pesquisa de campo com crianças que cursavam a terceira série do Ensino Fundamental, a fim de analisar o modo como procediam à leitura dessas narrativas. A opção por estudar os processos de leitura de indivíduos de terceira série deve-se ao fato de que, nessa etapa, os alunos já têm condiçóes de realizar uma leitura fluente da palavra, além de possuírem habilidades para compreender a imagem mesmo antes de frequentar a escola. $\mathrm{O}$ referencial teórico empregado nesses estudos procura dar conta da natureza da literatura produzida para a infância (ZILBERMAN, 1998) e de princípios inerentes ao ato da leitura (ISER, 1976; KLEIMAN, 2000). Parte-se do pressuposto de que o texto precisa da ação do leitor para sua efetivação, uma vez que se apresenta incompleto pelas lacunas inerentes à sua estrutura e o sujeito leitor deve completar esses vazios com sua experiência de vida, expectativas e conhecimentos (ISER, 1976).

Além de textos literários infantis, como os citados, o projeto utilizou como material de estudo o processo de leitura de trinta estudantes que cursavam terceira série do Ensino Fundamental em escolas de Caxias do 
Sul. Os mesmos foram indicados pelas professoras titulares das turmas que selecionaram cinco entre os leitores que apresentavam maior fluência de leitura, de acordo com observação e avaliação docente. Após a seleçáo, as crianças e seus pais foram informados sobre os objetivos do projeto e a modalidade de entrevista individual a que o aluno seria submetido. Esses alunos pertenciam a seis escolas públicas do município, localizadas na área urbana e uma na área rural.

Os dados sobre a leitura das crianças foram levantados através de entrevistas episódicas (BAUER; GASKELL, 2003). A análise dos dados coletados indica que a criança atribui sentido a narrativas verbo-visuais a partir de sua interação com palavra e ilustração, estabelecendo relaçóes entre as duas linguagens. Entretanto, percebe-se também que as crianças entrevistadas privilegiaram os signos linguísticos, deixando de considerar aspectos ligados à visualidade. Essa constatação explica-se, possivelmente, pela abordagem dada à literatura infantil nos ambientes escolar e familiar que privilegia a linguagem verbal em detrimento da visual. Dessa forma, os resultados da investigação apontam para a necessidade de formar docentes que sejam leitores das duas linguagens e que possam atuar como mediadores de leitura junto ao público mirim.

Neste artigo, enfoca-se a obra $A h$, cambaxirra, se eu pudesse..., texto de Ana Maria Machado (2003) com ilustraçóes por Graça Lima. O estudo envolve duas perspectivas que se complementam: apresentam-se possibilidades de significação para a narrativa infantil em questão e buscase analisar o modo como o público mirim interage com palavra e imagem na leitura do livro. A investigação sobre a leitura das crianças é realizada a partir de dados obtidos em cinco entrevistas com alunos que leram a obra em questão e estudavam no mesmo estabelecimento de ensino. Neste estudo aplicam-se pressupostos da pesquisa qualitativa em educação, a partir de Eisner (1998), e reflexóes sobre a literatura infantil, valendo-se de contribuiçóes de Zilberman (1998), principalmente em Literatura infantil na escola.

\section{Palavra e ilustração de narrativa verbo-visual}

Recuperada da tradição popular, $A h$, cambaxirra, se eu pudesse... $(\mathrm{MACHADO}, 2003)^{4}$ possui a estrutura de conto cumulativo, própria 
das narrativas transmitidas oralmente, cuja repetição ajuda o ouvinte a memorizar a história. $\mathrm{O}$ pássaro cambaxirra faz um ninho no galho da árvore mais bonita da floresta, mas surge um lenhador para cortá-la. Ao pedir que ele não a derrube, ouve: "Ah, cambaxirra, se eu pudesse..." E o lenhador justifica-se afirmando que recebeu a ordem do capataz, uma pessoa de quem ele tem muito medo. Cambaxirra, então, procura o capataz, a fim de impedir que o lenhador corte a árvore. Mas o capataz também diz receber ordens, neste caso, do barão. "E morro de medo dele" (MACHADO, 2003, p. 11), conclui. Ela vai até o barão... Assim, o passarinho procura outros superiores que possam impedir a derrubada da árvore, ouvindo de todos a mesma resposta: "Ah, cambaxirra, se eu pudesse [...]". Repetem-se as ações ocorridas e acumulam-se personagens, numa espécie de "lenga-lenga". $\mathrm{O}$ conflito se resolve quando a protagonista chega até o imperador. Esse, sob a ameaça de a protagonista pedir ajuda de "todo mundo junto", ordena que a árvore não seja derrubada. Ocorre, então, a confraternização de todos sob a sombra da árvore.

Nas entrevistas, observou-se que a criança é atraída especialmente pela visualidade, sendo as cores e formas aspectos essenciais para a compreensão do texto, conforme referências de Parsons (1992) sobre os estágios de compreensão estética. $\mathrm{O}$ pesquisador demonstra que o primeiro estímulo da experiência estética situa-se na ativação da sensibilidade ao mundo da cor e da figuração que se apresenta. Dessa forma, para o leitor iniciante, o processo de leitura como um ato solitário tem como principal fator de atração e de mediaçáo o campo visual e estético, o que ficou evidente, durante as entrevistas, já que as crianças observaram atentamente as imagens, especialmente as mais coloridas. A concepção comum é que a ilustração teria uma função secundária, apenas de decoração da obra, e que a mesma não se constitui texto.

Esta pesquisa, no entanto, parte do pressuposto de que o texto é um todo, constituído por elementos linguísticos, paralinguísticos, extralinguísticos e paratextuais que se inter-relacionam e participam da organização de sentido. Genette (1982, p. 9) assinala que aspectos paratextuais são geradores de sentido. Entre eles, o autor destaca o título, subtítulos, prefácio, posfácio, epígrafe, ilustração e outros signos acessórios. De acordo com estudos dessa pesquisa que buscam analisar as implicaçóes de textos em leitores constata-se que os fatores externos ao código verbal, 
como o tamanho do livro e o suporte utilizado para a história, orientam a interação que ocorre durante a leitura.

Nessa investigação constatou-se que a criança percebe o livro como um conjunto, onde as linguagens verbal e visual (formato, tamanho, tipo de letra e papel; cor, estilo e técnica empregada nas ilustraçóes, como também seres priorizados pela visualidade) se inter-relacionam para constituir significados. Durante a leitura o sujeito recorre à ilustração para buscar referências que o auxiliem na compreensão da história; segundo os entrevistados a imagem confirma o que as palavras dizem, revelando uma concepção da visualidade como acessório. ${ }^{5}$ Os entrevistados afirmam que é possível ler sem a imagem, mas também indicam que a presença das duas linguagens orienta a leitura, oferecendo âncoras para o reconhecimento do universo focalizado.

Outra ideia que permeia as concepções sobre a presença da ilustração em obras, especialmente as infantis, é que a imagem restringe a imaginação do leitor. É preciso lembrar que aqui se fala em leitores iniciantes, os quais estão formando sua competência leitora e, portanto, ainda apresentam restriçóes no domínio de aspectos linguísticos como o vocabulário, as estruturas da língua e até mesmo a cultura em que está ambientada a história. Assim, as linguagens presentes no texto, seja verbal ou visual, estabelecem pontos referenciais das manifestações da cultura, criam espaços de inserção de significados no universo apresentado, além de serem veículos da experiência sensível. As múltiplas dimensóes do texto contribuem para a construçáo do sentido pelo leitor. Portanto, pode-se afirmar que os diferentes elementos textuais não restringem as possibilidades de leitura, pelo contrário, ampliam o universo de significação dos textos e a competência leitora. Um leitor competente tirará proveito das possíveis relaçóes que for capaz de estabelecer entre palavra e imagem, não se tornando dependente de uma ou de outra.

Embora o objeto deste estudo seja a leitura que a criança faz da obra e as relaçóes construídas entre as linguagens para a efetivação de sentido, é preciso lembrar que a qualidade do livro infantil é fator relevante para a leitura e envolve aspectos das linguagens que o constituem, nesse caso, dos códigos verbal e visual. Um bom texto verbal deve sugerir sentidos e jogar com a competência do leitor, apresentando certezas que são, no momento seguinte, postas em dúvida. A ilustração amplia as possibilidades semânticas da palavra, mostrando sentidos paralelamente a ela, antecipando-os ou extrapolando-a. A combinação das linguagens 
gera tanto certezas, como inquietações. É o que encontramos na obra $A h$, cambaxirra, se eu pudesse...

A articulação entre os universos de linguagem verbal e visual pode ser exemplificada nesse livro também pelo desfecho do conto, já que, após a resoluçáo do conflito no plano verbal, com a interferência do imperador, a narrativa se completa pela ilustração que abrange as duas páginas seguintes, as últimas do livro. A cena apresenta todos os personagens brindando em torno de uma longa mesa, embaixo da árvore que tem o galho mais bonito da floresta. Nobres, plebeus e o pássaro confraternizam com alegria tendo como centro a árvore sobrevivente. Além disso, a disposição dos personagens à mesa não obedece à ordem dos títulos de nobreza, denotando a ruptura da estrutura hierárquica baseada no medo e a construçáo de novos laços entre os personagens, unidos pela harmonia e pela amizade. Essa imagem acrescenta sentido ao texto escrito, revelando um espaço festivo e democrático em que impera a alegria de todos, talvez pela vitória do esforço da cambaxirra.

\section{Entre a ilustração e a palavra: idas e voltas na construção de sentido}

Analisando a leitura que as crianças entrevistadas fizeram da obra, podem-se apontar vários indícios da interação entre palavra e imagem no momento da construção de significado. Participam do conto figuras da nobreza que não fazem parte do universo infantil, mas as ilustrações dão essas referências ao leitor: através delas é possível visualizar o barão, o visconde, o marquês, personagens desconhecidos pela maioria das crianças. Embora esses conceitos possam ser explicados de outras maneiras, mediante uma exposição oral ou pela consulta ao dicionário, a imagem cumpre o papel de oferecer ao leitor informaçóes de que ele necessita para a compreensão do texto. Dessa forma, atua como recurso mediador para a leitura, tornando-a mais agradável e atraente ao leitor que começa a se aventurar no universo linguístico e imagético. Além disso, esses dados poderão ser apreendidos e utilizados pelos sujeitos em outras leituras e situaçóes.

A representação visual dos personagens dialoga com a palavra no momento da leitura. Além de fugir aos modelos convencionais e estereotipados, acrescenta sentido ao que é dito no código verbal, pois os 
personagens são tratados de forma caricatural, enfatizando aspectos que os identificam. Destacam-se, por exemplo, o capataz, com seu cabelo azul; o barão, cuja cabeça é muito pequena em relação ao corpo; o visconde (Figura 2a), cujas pernas são finas e compridas, enquanto sua barriga é enorme; e o marquês (Figura 2b), cuja cabeça é preponderante. É dessa forma caricaturizada que todas as figuras humanas são ilustradas: o imperador, o conde, o duque (Figura 2c).

Figura 2 - (a) Visconde, (b) Marquês e (c) Duque
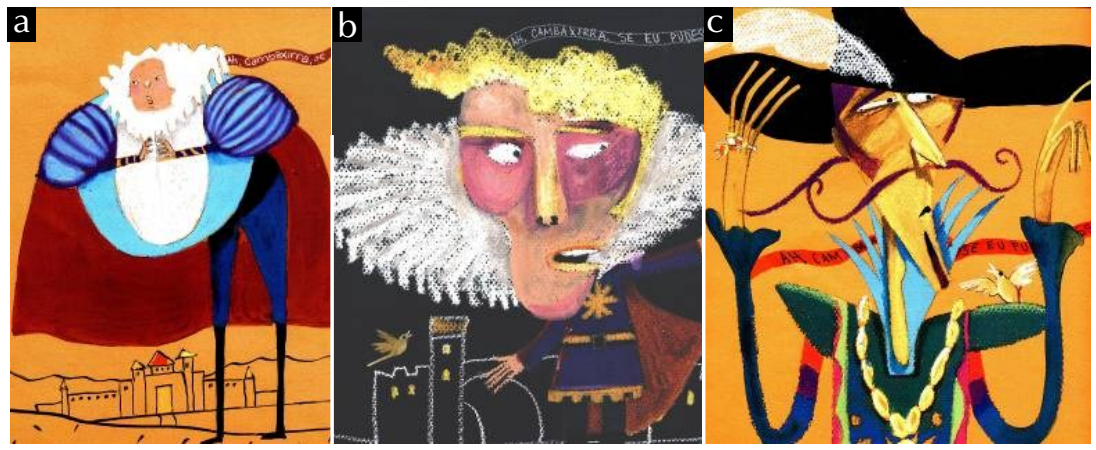

Fonte: Graça Lima (2003).

A representação caracteriza as pessoas e o ambiente, auxiliando na compreensão da hierarquia da nobreza. Dessa forma, o lenhador, o capataz e o barão, que ocupam as posiçóes iniciais na cadeia de poder, são caracterizados por vestuário simples. Os que possuem títulos mais elevados, como o conde, o marquês e o duque, ostentam jóias e usam roupas sofisticadas. Além da indumentária, a aparência física denota, em alguns momentos, fragilidade e, em outros, truculência, caracterizando as ambivalentes relaçôes de poder. $\mathrm{Na}$ representação das pernas finas ou das pernas curtas que sustentam uma estrutura pesada, como é o caso do visconde e do marquês, assim como a cabeça pequena em relação ao corpo, observada na ilustração do barão, remetendo a alguém que não toma decisóes, a imagem reforça a fragilidade. A cena que apresenta a atitude agressiva e autoritária do imperador, que grita com a cambaxirra e dá ordens apontando-lhe o dedo, retrata o desrespeito que permeia essas relaçóes e expressa o temor dos subordinados. $\mathrm{O}$ medo, mencionado no código verbal, está evidenciado também na fisionomia e na expressão 
corporal de cada personagem, com exceção da cambaxirra.

Mesmo os personagens que pertencem à nobreza e ostentam poder trazem em seus corpos marcas que demonstram a ambigüidade que reveste as relaçóes entre chefes e subordinados. A caracterização física dos personagens na ilustração, analisada anteriormente, leva à conclusão de que o poder exercido é frágil e até mesmo falso, o que é confirmado pela palavra em vários momentos da narrativa: "Estou só cumprindo ordens" (MACHADO, 2003). As relações de poder se estabelecem pelo medo e, no momento em que este deixa de existir - o que acontece no final do conto -, há espaço para a confraternização e a harmonia evidenciadas pela alegria e espontaneidade dos personagens na cena final da obra. Essa transformação não é explicitada pela palavra escrita.

É importante mencionar que, em sua leitura, as crianças não fizeram referência à hierarquia social sinalizada pela posição das personagens. Possivelmente, isso ocorreu porque esses dados não fazem parte do seu repertório, posto que se trata da representaçáo de personagens da época medieval, pertencentes à estrutura social do feudalismo. Ângela Kleiman (2000) define como fatores inerentes ao processamento cognitivo do texto o conhecimento prévio do leitor que envolve conhecimentos dos elementos linguísticos, das modalidades textuais e de mundo. Portanto, não houve menção a esse modo de organização da sociedade porque o leitor não tem referências contextuais para compreendê-lo. Porém, a apresentação visual das personagens auxilia no processo de significação, configurando uma imagem mental, a qual, provavelmente, passa a fazer parte de um repertório que vai agregando dados na construção de conceitos pelo sujeito leitor.

A fuga ao convencional e ao estereotipado que envolve a representação dos personagens passa também pela maneira de retratar o espaço. A narrativa se desenvolve na floresta, concebida como um lugar muito verde, habitado por animais, pela maioria dos leitores. No entanto, a imagem apresenta, desde a capa e a contracapa, árvores tratadas de uma forma singular: são coloridas - vermelhas, amarelas, azuis, laranja, com detalhes em manchas, traços e círculos - e multiformes, habitadas por pequenos pássaros, também coloridos em preto, vermelho e branco. A "árvore de galho mais bonito" onde a cambaxirra estava construindo seu ninho tem o tronco arroxeado e folhas magenta (MACHADO, 2003).

Nota-se uma ruptura na forma de se representar uma floresta. A 
convenção de árvores verdes não condiz com a realidade nem com as imagens da obra. $\mathrm{Na}$ natureza ocorrem constantes mudanças, com a vegetação adquirindo diferentes matizes ao longo das estaçóes e em diferentes regióes. Ao propor uma forma perspicaz de olhá-las e retratá-las, a ilustradora participa da brincadeira de inventar das crianças, estimulando a percepção e a imaginação dos leitores e não as restringindo, como faria a ilustração estereotipada. A obra inova pela forma como representa personagens e cenários e também demonstra cuidado e qualidade na produção visual e verbal. O livro e a infância têm um olhar livre para apreender o universo.

Embora a investigação comprove que a visualidade cumpre um papel na obra infantil, muitas vezes os leitores entrevistados desconsideraram aspectos apresentados pela ilustração e não referidos no texto verbal. Entre outros, os cenários parecem passar despercebidos, não sendo mencionados, embora auxiliem a compor a identidade dos personagens por caracterizarem o lugar onde eles vivem. Enquanto o capataz mora em uma casa, os nobres vivem em castelos e palácios, cujo tamanho e suntuosidade aumentam de acordo com os títulos que detêm: barão, visconde, conde, marquês e duque. Esses dados não foram mencionados pelas crianças durante as entrevistas, mas devem ser considerados pelos leitores, dado que os auxiliam a perceber a hierarquia existente entre os personagens.

Outra ilustração ignorada pela maioria dos sujeitos foi a que representa o desfecho do conto. Ao ser questionada sobre o final da história, a maioria das crianças limitou-se a afirmar que a árvore não foi cortada, ignorando aspectos da última imagem que mostra uma festa. $\mathrm{O}$ desfecho do conto, apresentado pela ilustração, foi citado por apenas um entre os cinco entrevistados. Esse procedimento interpretativo que prioriza o texto verbal denota a falta de familiaridade com a leitura das imagens, uma vez que o universo pictórico é tratado pelo leitor como mera decoração e não como parte integrante e geradora de significação. A não-leitura da imagem pela criança é consequência provável da adoção da hegemonia da palavra, referenciada pela escola e presente no discurso do adulto, sejam eles seus familiares ou professores.

Os leitores entrevistados priorizaram a linguagem verbal e citaram como aspecto positivo na obra a valorização do meio ambiente. Embora essa temática esteja presente, ela é periférica no contexto do conto. A forma de lidar com o poder, de enfrentar conflitos e sentimentos como a insegurança e o medo são metáforas da narrativa que foram ignoradas 
pelos leitores. As crianças evidenciaram uma tendência de ler para adquirir valores e normas de conduta ou para buscar conhecimentos relacionados a conteúdos aprendidos na sala de aula, o que constitui um reflexo da concepção de literatura infantil como instrumento de ensino, disseminada nos ambientes escolar e familiar. Aliás, a pedagogização acompanha o gênero desde sua origem; os primeiros contos, adaptados da oralidade para o público infantil, tinham objetivo claro de imprimir, nos pequenos, valores e normas definidas pelos adultos. O livro infantil nasceu como instrumento de ensino e, quase quatro séculos depois, tende a desempenhar papel doutrinador, especialmente na sala de aula.

Com a evolução do gênero, obras destinadas à criança adquiriram o estatuto de texto artístico, passaram a ser consideradas literárias. Tais textos, por serem dirigidos ao receptor mirim, devem atender às expectativas do público e possuir cunho emancipatório. Para Zilberman (1998, p. 25), a literatura infantil é levada a realizar sua função formadora, que não se confunde com uma missão pedagógica. De acordo com a autora a leitura do texto artístico oferece à criança o conhecimento do mundo e de si mesma através da realidade criada pela fantasia do escritor e, dessa forma, propicia a emancipação pessoal. Assim, seu alcance ultrapassa a mera função de controle do pensar e de formas de conduta.

\section{Considerações finais}

Os dados levantados pela pesquisa sinalizam que a visão pedagogizante de literatura infantil, ainda em vigor nas escolas, restringe a formação de leitores autônomos. Isso indica a necessidade de mudanças urgentes na abordagem do gênero que é, antes de tudo, arte. E como texto artístico sua leitura é uma possibilidade para compreender a si mesmo e ao mundo e nele atuar, além de propiciar a experiência estética, desenvolver a sensibilidade, a imaginação, a criatividade e o pensamento de seus leitores, sejam eles professores ou alunos.

$\mathrm{Na}$ perspectiva apresentada neste artigo, em que se considera o livro infantil como um objeto constituído por mais de uma linguagem - em especial por palavra e ilustração -, a instrumentalização de educandos e educadores para interagirem com a diversidade presente nas obras torna-se imprescindível. Acredita-se que, através da instrumentalização para a leitura 
literária, ambos se tornariam capazes de atribuir sentido a esses textos, o que lhes daria acesso à riqueza formativa dessas obras - competência que se constatou deficitária na leitura das crianças entrevistadas na pesquisa.

Além disso, considera-se que as habilidades envolvidas na leitura de textos literários não contribuem apenas para a formação de leitores de literatura, mas auxiliam a leitura de diferentes textos. Um exemplo disso pode ser encontrado na publicidade. $\mathrm{O}$ contexto atual disponibiliza textos publicitários e jornalísticos os quais exigem, para que sua leitura se efetive, a capacidade de relacionar as linguagens que os constituem, ou seja, uma habilidade envolvida também na leitura de textos infantis, conforme demonstrado na análise da obra $A h$, cambaxirra, se eu pudesse... (MACHADO, 2003). O desafio posto pelo analfabetismo funcional também se manifesta no cotidiano da cultura midiática, televisiva ou virtual. A aprendizagem da leitura do texto literário poderá promover a transposição de habilidades que revertam na tomada de consciência em relação aos textos com os quais lidamos no cotidiano. $\mathrm{O}$ conhecimento das relaçóes entre as linguagens e as possibilidades semânticas contribuiria para substituir o descompromisso de um ver por ver o livro por um olhar ativo, competente, que apreende essa realidade construída. Para tanto, é necessário compreender, desvendar a ação de todos os seus elementos constituintes e tratá-los igualmente como parte integrante da leitura, os quais são tecidos artisticamente na literatura infantil.

Por que, então, ignorar a interação entre linguagens no texto literário, entendido também como texto artístico? Defender a supremacia da palavra em detrimento da imagem seria o mesmo que escolher entre Portinari e Machado de Assis, Villa Lobos e Aleijadinho. É ingenuidade não reconhecer que cada artista domina linguagens específicas, que ativam diferentes sentidos em seus leitores. As obras artísticas traduzem experiências inerentes à condição humana, possíveis de serem compartilhadas pelos leitores. Transitar pelas diferentes linguagens permite conhecer suas sutilezas e suas formas de tradução e ainda ter acesso ao universo que encerram; o mesmo ocorre pelo contato com textos que as combinam, ativando cognitivamente diferentes competências e criando novas formas de compreensão.

Essa compreensão de texto literário implica uma abordagem pedagógica diferenciada que considera a interação entre linguagens no processo de leitura e auxilia o aluno a perceber e a significar essa 
ocorrência. Dessa forma, considerando que a palavra e a visualidade participam do processo de significação do texto, o docente precisa observar, na seleção de uma obra, não apenas aspectos relativos à trama ou ao discurso verbal, mas também os elementos visuais que compóem os livros infantis ou infanto-juvenis. Em outras palavras, é preciso estar atento à qualidade visual das obras. Assim como nem todos os livros possuem boa construção lingüística, nem todos possuem boa ilustração e configuração gráfica. Nesse sentido, é preciso lembrar que o professor deve desenvolver sua habilidade de leitura para que, antecipadamente, perceba qualidades nos livros que indicará aos seus alunos ou com os quais almeja desenvolver uma ação pedagógica. Além disso, deveria conviver com diferentes modalidades de produçóes plásticas, não apenas com a diversidade linguística. Sendo um leitor competente, capaz de interagir com as diferentes linguagens, poderá analisar e estabelecer critérios de seleção de livros, entre eles, a qualidade da ilustração, buscando obras em que o verbal e o não-verbal ampliem as possibilidades de compreensão da obra.

Propóe-se, pois, aos que se ocupam da problemática da educação redimensionar as concepçóes escolares de "leitura" e de "texto", substituindo a visão compartimentada e reducionista por outra que reconheça a multidimensionalidade dos processos. Porém, para que ocorram mudanças é preciso, primeiramente, gerar uma reflexão que leve à tomada de consciência sobre as formas de agir, os fatos e as situaçóes que precisam ser modificados, apontando também atos que concretizem a reflexão. Para tanto, professores e alunos devem investir em uma postura autocrítica, na formação continuada, instrumentalizando-se e arriscandose à leitura estético-visual, acolhendo e dialogando com o livro infantil, incorporando novos conhecimentos transpostos às práticas de leitura no cotidiano do espaço educativo. Mergulhar no texto literário para a infância é uma oportunidade para aprendizagens mais complexas, transitando pelo campo da arte, da linguagem, da cultura e da vida, a fim de atingir o objetivo maior que é conhecer o meio onde se está inserido e conhecer-se, finalidade da expressão artística. 


\section{Notas}

1 A capa da primeira edição da obra de Perrault está disponível no site $<$ http://expositions.bnf.fr/contes/feuille/perrault/index.htm>.

2 A Fundação nacional do Livro infantil e Juvenil (FNLIJ) julga e premia a produção literária destinada à infância e, em 2007, a obra Lampião \& Lancelote, de Fernando Vilela (2006), que explora o entrelaçamento entre verbal e visual, recebeu três prêmios: Revelaçáo Escritor, Melhor Projeto Editorial e Melhor Ilustração, sinalizando a noção de que o livro é um objeto sincrético.

3 Este estudo resulta da pesquisa "A produção de sentido e a interação texto-leitor na literatura infantil", realizada na Universidade de Caxias do Sul (UCS), entre 2003 e 2006, com o apoio da FAPERGS.

4 Essa história havia sido publicada por Ana Maria Machado, em 1991, editora Salamandra, com ilustraçóes de Gerson Conforto. As ilustrações dessa edição são figurativas. Pode-se afirmar que a última edição, ilustrada por Graça Lima, revitaliza a narrativa através da nova roupagem conferida a história.

5 Luis Camargo (1995), com base em Jakobson, propóe funções para a ilustração no livro infantil. Na coleta de dados realizada nesta investigação é possível perceber o papel dessas funçóes.

\section{REFERÊNCIAS}

BARROS, Manoel de. Exercícios de ser criança. Bordados de Antônia Zulma Diniz, Ângela, Marilu, Martha e Sávia Dumont sobre desenhos de Demóstenes. Rio de Janeiro: Salamandra, 1999.

BAUER, Martin W.; GASKELL, George. Pesquisa qualitativa com texto, imagem e som: um manual prático. 2. ed. Petrópolis: Vozes, 2003.

BERNARDI JÚNIOR, Hermes. Planeta Caiqueria. Ilustraçóes de André Neves. Porto Alegre: Projeto, 2003.

BRASIL. ENEM - Exame Nacional do Ensino Médio. Disponível em: <http://download.inep.gov.br/educacao_basica/enem/downloads/2009/ Enem2009_matriz.pdf>. Acesso em: 10 fev. 2011. 
CAMARGO, Luís. Ilustração no livro infantil. Belo Horizonte: Lê, 1995. EISNER, Eliot. El ojo ilustrado: indagación cualitativa y mejora de la práctica educativa. Barcelona: Paidós, 1998.

GENETTE, Gerard. Palimpsestes: a littérature au second degré. Paris: Seuil, 1982.

ISER, Wolfgang. L'acte de la lecture: théorie de l'effet esthétique. Bruxelas: Mardaga, 1976.

KLEIMAN, Ângela. Texto e leitor: aspectos cognitivos da leitura. 8. ed. Campinas: Pontes, 2000.

LAGO, Angela. Indo não sei aonde buscar não sei o quê. Ilustraçóes da autora. Rio de Janeiro: RHJ, 2000.

MACHADO, Ana Maria. Ah, cambaxirra, se eu pudesse... São Paulo: FTD, 2003.

PARSONS, Michael J. Compreender a arte: uma abordagem à experiência estética do ponto de vista do desenvolvimento cognitivo. Lisboa: Presença, 1992.

PERRAULT, Charles. Capa da primeira edição de Histoires ou Contes $d u$ temps passé avec des moralitez. Disponível em: <http://expositions.bnf.fr/ contes/feuille/perrault/index.htm>. Acesso em: 10 fev. 2011.

PERIN, Fabiana Tasca. Os bolsos do mundo. Ilustraçóes de Joana Puglia. Santa Cruz do Sul: EDUNISC, 2003.

PROGRAMA PARA AVALIAÇÃO INTERNACIONAL DE ESTUDANTES (PISA). Disponível em: <http://nces.ed.gov/surveys/ pisa/pisa2009highlights_2.asp>. Acesso em: 10 nov. 2010.

VILELA, Fernando. Lampião \& Lancelote. Texto e ilustração do autor. São Paulo: Cosac Naify, 2006.

ZILBERMAN, Regina. Literatura infantil na escola. 10. ed. São Paulo: Global, 1998. 


\section{Image and word in the reading of narrative}

\section{Abstract}

Contemporary children's stories explore the various languages of children's literature - words and illustration. A reading of these works allows the reader to construct meaning through the interaction between verbal and visual codes. To analyze this process, a study was conducted of the narrative Ah cambaxirra, se eu pudesse..., by Ana Maria Machado and Graça Lima (2003). It focused on two aspects: the analysis of the possible readings proposed by the language, based on Genette (1982), Iser (1976), Kleiman (2002), Parsons (1992) and Zilberman (1998), and the meanings constructed by third grade children, according to qualitative research principals (Bauer; Gaskell, 2003; Eisner, 1998). The study confirms the construction of meanings in the text through the relation between the languages. Nevertheless, the analysis of children's reading reveals that the meanings constructed by the children emphasize the words over the visual aspects. It is believed that the children's perspective is a result of the approach they are taught at school, which does not form proficient readers. The article aims to contribute to research in this area and to provide tools for reading mediators.

Keywords: Reading. Children's Literature. Illustration.

\section{Imagen y palabra en la lectura de la narrativa}

\section{Resumen}

La realización del libro infantil actual se utiliza de distintos lenguajes en su organización - la palabra y la ilustración. La lectura de estos textos hace posible al lector la construcción de significados a causa de la interacción entre los sistemas verbal y visual. Para investigar este proceso, se estudia el libro $A$ h, cambaxirra, se eu pudesse..., de Ana Maria Machado y Graça Lima (2003). Son destacados dos puntos principales de análisis: las posibilidades de lectura desde los diversos lenguajes, teorizados por Genette (1982), Iser (1976), Kleiman (2002), Parsons (1992) y Zilberman (1998); y los sentidos construidos por niños de tercer ańo de la enseñanza fundamental. Se utilizan las bases de la pesquisa con aportes de Bauer \& Gaskell (2003) y Eisner (1998). Los estudios confirman el aumento de sentidos del texto, por la articulación entre los lenguajes. Sin embargo, el análisis de la lectura que hacen los niños indica que los sentidos construidos privilegian la palabra, en lugar de los aspectos visuales. Se puede creer que lo que ha sido observado en la lectura de los nińos es un efecto del abordaje de la literatura en la escuela, que no desarrolla lectores competentes. El artículo pretende contribuir con investigaciones en el campo, así como cooperar en la instrucción de formadores de lectura.

Palabras clave: Lectura. Literatura infantil. Ilustración. 


\section{Flávia Brocchetto Ramos}

E-mail: ramos.fb@gmail.com

Neiva Senaide Petry Panozzo

E-mail: neiva.panozzo@gmail.com

\section{Taciana Zanolla}

E-mail: tacianazanolla@gmail.com

Recebido em: 31/3/2010

Versáo final recebida em: $3 / 3 / 2011$

Aprovado em: 29/3/2011 